\title{
Using Local Searches Algorithms with Ant Colony Optimization for the Solution of TSP Problems
}

\author{
Renas Rajab Asaad ${ }^{1}$ and Nisreen Luqman Abdulnabi ${ }^{2}$ \\ ${ }^{1}$ College of Computer Science and Information Technology, Nawroz University, Duhok, Kurdistan Region - Iraq \\ ${ }^{2}$ College of Economics and Administrative, University of Duhok, Duhok, Kurdistan Region - Iraq
}

\begin{abstract}
Swarm intelligence is a relatively new approach to problem solving that takes inspiration from the social behaviors of insects and other animals. Ants, in particular, have inspired a number of methods and techniques among which the most studied and successful is the general-purpose optimization technique, also known as ant colony optimization, In computer science and operations research, the ant colony optimization algorithm (ACO) is a probabilistic technique for solving computational problems which can be reduced to finding good paths through graphs. Ant Colony Optimization (ACO) algorithm is used to arrive at the best solution for TSP. In this article, the researcher has introduced ways to use a great deluge algorithm with the ACO algorithm to increase the ability of the ACO in finding the best tour (optimal tour). Results are given for different TSP problems by using ACO with great deluge and other local search algorithms.

KEYWORDS : Travels Salesman Problem (TSP), Ant Colony Algorithm (ACO), Great Deluge Algorithm, Optimization, opt-algorithm.

\section{INTRODUCTION}

Ant Colony Optimization (ACO) uses the behavior of ants for finding optimal paths for TSP problems. Adding Great Deluge algorithm to ACO increase the efficiency of ACO to get a better result in a minimum time. Great Deluge algorithm generates new tour from an old tour by finding neighbor of the cities in the tour by using local search methods, in this article we used 2-Opt algorithm and N-Shift.[1].

\section{Travelling Salesman Problem (TSP)}

TSP is an NP-hard problem in combinatorial optimization [1]. Given a set of cities in which every city must be visited once only and return to the starting city for completing a tour such that the length of the tour is the shortest among all possible tours [1,2]. In general there are two different kinds of TSP, the Symmetric TSP (STSP)

cities. Formally, the TSP is a complete weighted graph G $(\mathrm{N}, \mathrm{A})$ where $\mathrm{N}$ is the set of cities which must be visits, and $A(i, j)$ is the set of arcs connecting the cities together [1]. The length between city $A_{i}$ and $A_{j}$ can be represented as $d_{i j}$. Thus the optimal (minimum length) tour to the TSP can be found as shown below.

$$
\text { Btour }=\left(\sum_{i=1}^{n-1} d_{p(i) p(i+1)}\right)+d_{p(n) p(1)}
$$

Where $\mathrm{p}$ is a probability list of cities with minimum distance between city $\left(\mathrm{p}_{\mathrm{i}}\right.$ and $\left.\mathrm{p}_{\mathrm{i}+1}\right)[2,3]$.

\subsection{Ant Colony Optimization (ACO) and TSP}

The Ant Colony Optimization (ACO) heuristic is an inspiration of the real ant behavior to find the shortest path between the food and ant's nest [1,2]. As shown in figure 1.
\end{abstract} and the Asymmetric TSP (ATSP).the number of tours in the ATSP is (n-1)!, Whereas it is (n-1)!/2 in STSP for $n$

Academic Journal of Nawroz University

(AJNU) Volume 7, No 3 (2018).

Received 16 Feb 2018.

Regular research paper : Published 20 June 2018

Corresponding author's e-mail : renas_rekany@yahoo.com

Copyright (C2018 Renas Rajab Asaad.

This is an open access article distributed under the

Creative Commons Attribution License. 


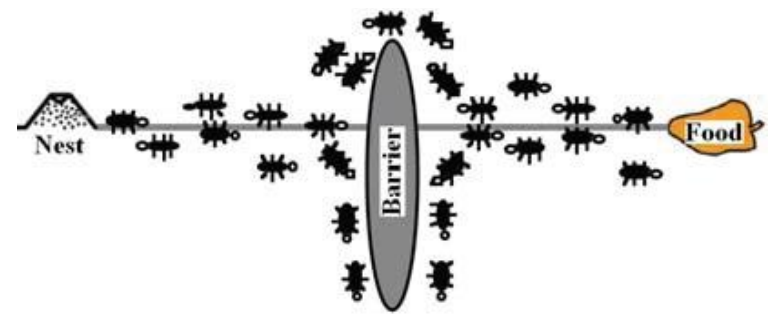

Figure (1) : ACO

The behavior of each ant in nature

- First each ant randomly, laying down a pheromone trail in its path for food searching.

- If any ant founds a food, return to the nest laying down a pheromone trail

- If in a path the pheromone increased the other ant follow that path.

ACO use the same procedure to find the optimal (minimum length) path to the TSP problem, in a given set of cities at first each ant use the pheromone trail to choose a nearest city to its current position and adds cities one by one until it complete the tour by visiting all cities and back to the starting city. After each ant complete its tour ACO update the pheromone trail. ACO pseudo code is shown below.

Initialize

Loop

Each ant is positioned on a starting node

Loop

Each ant applies a state transition rule to incrementally build a solution and a local pheromone updating rule

Until all ants have built a complete solution

A global pheromone updating rule is applied

Until end condition

\subsection{Great deluge algorithm}

It is a comprehensive approach for solving optimization problems. It use local searches algorithm to find the neighbor of the current solution and compare it with the fitness of the best solution and the water level (WL) if its better it replaces common solution (New_solution) with best results (Best_solution). This action continues until stop conditions is provided [4]. Great Deluge pseudo code is shown below.

Choose an initial configuration as Old_solution and

Best_solution

Choose $\Delta \mathrm{WL}$ and WL

For $\mathrm{n}=0$ to \# of iterations

Generate a $\mathrm{New}_{-}$solution from neighbor of Old solution

If Fitness (New_solution) $<\mathrm{WL}$

If Fitness (New_solution) < (Best_solution)

Old_solution := New_solution

End If

End If

$\mathrm{WL}=\mathrm{WL}-\Delta \mathrm{WL}$

End For

\subsection{Finding neighbor for Great Deluge Algorithm}

In this paper two methods are used to find neighbors to be use by Great Deluge algorithm which are (N-Shift method and 2-Opt method).

\subsubsection{N-Shift :}

This method changes the order of cities in the current path. It chooses a city and change with all other cities in the list gradually as shown below.

Initial $A=>B=>C=>D=>E=>F$

Step1 $B=>A=>C=>D=>E=>F$

Step2 $C=>B=>A=>D=>E=>F$

N-Sift pseudo code is shown below

for $i=1$ to number of cities -1

for $j=i+1$ to number of cities

replace the position of city(i) and city(j)

End End

\subsubsection{2-Opt algorithm}

The 2-opt algorithm basically removes two edges from the tour, and reconnects the two paths in reverse order. This is often referred to as a 2-opt move [5,6,7].

The figure 2 is showing that the tour $\{1,2,3,4,5,6,7,8\}$ After applying 2-opt algorithm it Become \{ $1,2,6,5,4,3,7,8$,
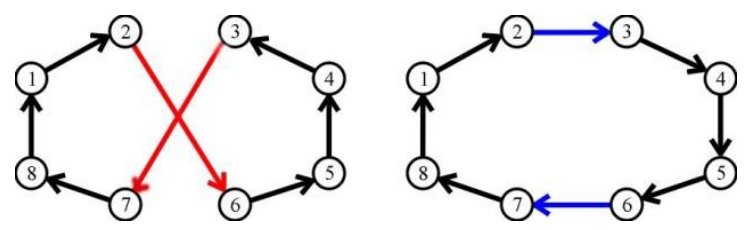

Figure (2) : 2-Opt algorithm

2-Opt pseudo code is shown below.

Require : Tour T .

Let $\mathrm{Ti} \leftarrow$ Cluster $(\mathrm{Ti})$.

for $\mathrm{x} \leftarrow 1,2, \ldots, \mathrm{m}-2$ do

Calculate the shortest paths along the tour $\mathrm{T}$ from every vertex in $\mathrm{Ty}$ to every vertex in $\mathrm{T} x+1$ and from every vertex in Ty +1 to every vertex in $\mathrm{T} x$ for every $y=x+2$, $x+3, \ldots, \min \{m, x+m-2\}$.

for $y \leftarrow x+2, x+3, \ldots, \min \{m, x+m-2\}$ do

Construct a layered network $L$ as in Figure $2 b$.

Apply CO to L to get the shortest cycle C.

if $w(C)<w(T)$ then

Replace $\mathrm{T}$ with $\mathrm{C}$.

Restart the whole algorithm.

2.4 Using N-Shift and 2-Opt with Great Deluge algorithm

N-Shift or 2-Opt algorithm can be used for (Generate a New_solution from the Old_solution) In Great Deluge algorithm. (2-Opt \& N-Shift) inside Great Deluge pseudo code is shown below.

Choose an initial configuration as Old_solution and Best_solution

Choose $\Delta \mathrm{WL}$ and WL 
For $n=0$ to \# of iterations

N-Shift OR 2-Opt

If Fitness (New_solution) $>$ WL

If Fitness (New_solution) $>$ (Best_solution)

Old_solution $:=\mathrm{New}_{-}$solution

End If

End If

$\mathrm{WL}=\mathrm{WL}+\Delta \mathrm{WL}$

End For

\subsection{Inserting Great Deluge to ACO}

Inserting Great Deluge algorithm to ACO make the result of ACO approaches or equal to the optimal one. Great Deluge with (N-Shift OR 2-Opt) algorithm are used either inside ACO algorithm or at the end of ACO algorithm.

\subsubsection{Using Great Deluge inside ACO}

When Great Deluge is used inside the ACO algorithm it tries to optimize the results of ACO at each loop. Great Deluge inside ACO pseudo code is shown below.

Initialize

Loop

Each ant is positioned on a starting node

Loop

Each ant applies a state transition rule to incrementally build a solution and a local pheromone updating rule Apply Great Deluge with (N-shift OR 2-Opt) to the current tour

Until all ants have built a complete solution A global pheromone updating rule is applied Until end condition

\subsubsection{Using Grete Deluge at the end of ACO}

When Great Deluge is used at the end of ACO algorithm it tries to optimize the best solution found by ACO. Great Deluge at the end of ACO pseudo code is shown below.

Initialize

Loop

Each ant is positioned on a starting node

Loop

Each ant applies a state transition rule to incrementally build a solution

and a local pheromone updating rule

Until all ants have built a complete solution

A global pheromone updating rule is applied

Until end condition

Apply Great Deluge with (N-shift OR 2-Opt) to the best tour found by ACO

\section{Implementation and Results}

This section presents the performance of adapting great deluge algorithm and other local search (N-Shift, 2-Opt) algorithms to the (ACO) algorithm which are thus classified into three different table of results, the first table for the results of ACO algorithm before adding any other algorithm to it and two other tables, a table for the results of Great Deluge and 2-Opt (inside \& at the end of) ACO while the other table shows the results of Great Deluge and N-Shift (inside \& at the end of) ACO. The results are shown for different TSP problem from (TSPLIB95).

3.1ACO results

Initial ACO results before inserting any other algorithms to it.

Table (1) : ACO results

\begin{tabular}{|c|c|c|c|}
\hline TSP problem & Optimal Solution & $\begin{array}{c}\text { ACO result in 200 } \\
\text { iteration }\end{array}$ & $\begin{array}{c}\text { ACO result in 500 } \\
\text { iteration }\end{array}$ \\
\hline Att48 & 10628 & Fitness 11753 & Fitness 11753 \\
\hline ch130 & 6110 & Fitness 6941.6 & Fitness 6941.6 \\
\hline berlin52 & 7542 & Fitness 8092 & Fitness 8072 \\
\hline ch150 & 6528 & Fitness 6871 & Fitness 6871 \\
\hline eil51 & 426 & Fitness 472 & Fitness 472 \\
\hline st70 & 675 & Fitness 746 & Fitness 746 \\
\hline
\end{tabular}

\section{I.Result of ACO with Great Deluge and N-Shift algorithm}

N-Shift is used in two different ways (inside ACO \& at the end of ACO) which gives different results. For (att48) the best solution for Great deluge and N-shift inside ACO is (11483) while it was (11904) when great deluge and N-shift are at the end of ACO. 
Table (2) : Result of ACO with Great Deluge and N-Shift algorithm

\begin{tabular}{|c|c|c|c|}
\hline $\begin{array}{c}\text { TSP } \\
\text { Problem }\end{array}$ & $\begin{array}{l}\text { Optimal } \\
\text { Solution }\end{array}$ & $\begin{array}{c}\text { N-shift and great deluge } \\
\text { \# Iteration }=10 \text { inside ACO- } \\
\text { TSP } \\
\text { \# iteration }=10\end{array}$ & $\begin{array}{c}\text { N-shift and great deluge } \\
\text { \# Iteration }=10 \text { at the end of ACO- } \\
\text { TSP } \\
\text { \# iteration }=10\end{array}$ \\
\hline \multirow{3}{*}{ Att 48} & \multirow{3}{*}{10628} & $\begin{array}{c}\text { Best tour Fitness } \\
11483\end{array}$ & $\begin{array}{c}\text { Best tour Fitness } \\
11904\end{array}$ \\
\hline & & $\begin{array}{c}\text { Elapsed time } \\
179.967442\end{array}$ & $\begin{array}{l}\text { Elapsed time } \\
5.188908\end{array}$ \\
\hline & & $\begin{array}{c}\text { Evaluation function } \\
32486881\end{array}$ & $\begin{array}{l}\text { Evaluation function } \\
11760\end{array}$ \\
\hline \multirow{3}{*}{ ch130 } & \multirow{3}{*}{6110} & $\begin{array}{c}\text { Best tour Fitness } \\
6839\end{array}$ & $\begin{array}{c}\text { Best tour Fitness } \\
6906\end{array}$ \\
\hline & & $\begin{array}{l}\text { Evaluation function }= \\
654031301\end{array}$ & $\begin{array}{l}\text { Evaluation function }= \\
\qquad 85150\end{array}$ \\
\hline & & $\begin{array}{c}\text { Elapsed time } \\
4887.513595 \text { seconds }\end{array}$ & $\begin{array}{c}\text { Elapsed time } \\
30.899352 \text { seconds }\end{array}$ \\
\hline \multirow{3}{*}{ berlin52 } & \multirow{3}{*}{7542} & $\begin{array}{c}\text { Best tour Fitness } \\
8035\end{array}$ & $\begin{array}{l}\text { Best tour Fitness } \\
8087\end{array}$ \\
\hline & & $\begin{array}{c}\text { Elapsed time } \\
235.027542 \text { seconds }\end{array}$ & $\begin{array}{c}\text { Elapsed time } \\
7.219683 \text { seconds }\end{array}$ \\
\hline & & $\begin{array}{c}\text { Evaluation function } \\
41371721\end{array}$ & $\begin{array}{l}\text { Evaluation function } \\
13780\end{array}$ \\
\hline \multirow{3}{*}{ ch150 } & \multirow{3}{*}{6528} & $\begin{array}{c}\text { Best tour Fitness } \\
6858\end{array}$ & $\begin{array}{l}\text { Best tour Fitness } \\
6954\end{array}$ \\
\hline & & $\begin{array}{c}\text { Elapsed time } \\
8025.759414 \text { seconds }\end{array}$ & $\begin{array}{c}\text { Elapsed time } \\
\text { 40.799448seconds }\end{array}$ \\
\hline & & $\begin{array}{c}\text { Evaluation function } \\
1.0058 \mathrm{e}+009\end{array}$ & $\begin{array}{c}\text { Evaluation function } \\
113250\end{array}$ \\
\hline \multirow{3}{*}{ eil51 } & \multirow{3}{*}{426} & $\begin{array}{c}\text { Best tour Fitness } \\
444 \\
\end{array}$ & $\begin{array}{c}\text { Best tour Fitness } \\
461 \\
\end{array}$ \\
\hline & & $\begin{array}{c}\text { Elapsed time } \\
221.497929 \text { second }\end{array}$ & $\begin{array}{c}\text { Elapsed time } \\
5.615070 \text { second }\end{array}$ \\
\hline & & $\begin{array}{l}\text { Evaluation function } \\
39015511\end{array}$ & $\begin{array}{l}\text { Evaluation function } \\
13260\end{array}$ \\
\hline \multirow{3}{*}{ st70 } & \multirow{3}{*}{675} & $\begin{array}{c}\text { Best tour Fitness } \\
700 \\
\end{array}$ & $\begin{array}{c}\text { Best tour Fitness } \\
716 \\
\end{array}$ \\
\hline & & $\begin{array}{c}\text { Elapsed time } \\
607.734886 \text { seconds }\end{array}$ & $\begin{array}{c}\text { Elapsed time } \\
9.443444 \text { seconds }\end{array}$ \\
\hline & & $\begin{array}{l}\text { Evaluation function } \\
101430701\end{array}$ & $\begin{array}{l}\text { Evaluation function } \\
24850\end{array}$ \\
\hline
\end{tabular}




\section{II.Result of ACO with Great Deluge and 2-Opt algorithm}

2-Opt algorithm as N-Shift also is used (inside ACO \& at the end of ACO) which gives different results. For (att48) the best solution for Great deluge and 2-Opt inside ACO is (10798) while it was (11154) when great deluge and 2-Opt are at the end of ACO.

Table (3) : Result of ACO with Great Deluge and 2-Opt algorithm

\begin{tabular}{|c|c|c|c|}
\hline Problem & $\begin{array}{l}\text { Optimal } \\
\text { Solution }\end{array}$ & $\begin{array}{c}\text { 2-Opt and great deluge } \\
\text { \# Iteration=10 inside ACO- } \\
\text { TSP } \\
\# \text { iteration }=10\end{array}$ & $\begin{array}{c}\text { 2-Opt and great deluge } \\
\text { \# Iteration=10 at the end of ACO- } \\
\text { TSP } \\
\text { \# iteration }=10\end{array}$ \\
\hline \multirow{3}{*}{ att 48} & \multirow{3}{*}{10628} & $\begin{array}{c}\text { Best tour Fitness } \\
10798\end{array}$ & $\begin{array}{c}\text { Best tour Fitness } \\
11154\end{array}$ \\
\hline & & $\begin{array}{l}\text { Elapsed time } \\
422.227777 \mathrm{~s}\end{array}$ & $\begin{array}{c}\text { Elapsed time } \\
5.999922 \text { seconds. }\end{array}$ \\
\hline & & $\begin{array}{c}\text { Evaluation function } \\
24141096 \\
\end{array}$ & $\begin{array}{l}\text { Evaluation function } \\
32941 \\
\end{array}$ \\
\hline \multirow{3}{*}{$\operatorname{ch} 130$} & \multirow{3}{*}{6110} & $\begin{array}{l}\text { Best tour Fitness } \\
6347\end{array}$ & $\begin{array}{c}\text { Best tour Fitness } \\
6629\end{array}$ \\
\hline & & $\begin{array}{c}\text { Evaluation function }= \\
507978272\end{array}$ & $\begin{array}{c}\text { Evaluation function }= \\
228404\end{array}$ \\
\hline & & $\begin{array}{c}\text { Elapsed time } \\
8876.979989 \text { seconds }\end{array}$ & $\begin{array}{c}\text { Elapsed time } \\
31.515636 \text { seconds }\end{array}$ \\
\hline \multirow{3}{*}{ berlin52 } & \multirow{3}{*}{7542} & $\begin{array}{c}\text { Best tour Fitness } \\
7717 \\
\end{array}$ & $\begin{array}{c}\text { Best tour Fitness } \\
7884\end{array}$ \\
\hline & & $\begin{array}{c}\text { Elapsed time } \\
647.569437 \text { seconds }\end{array}$ & $\begin{array}{c}\text { Elapsed time } \\
6.764293 \text { seconds. }\end{array}$ \\
\hline & & $\begin{array}{c}\text { Evaluation function } \\
35654729\end{array}$ & $\begin{array}{l}\text { Evaluation function } \\
45617\end{array}$ \\
\hline \multirow{3}{*}{$\operatorname{ch} 150$} & \multirow{3}{*}{6528} & $\begin{array}{c}\text { Best tour Fitness } \\
6622 \\
\end{array}$ & $\begin{array}{c}\text { Best tour Fitness } \\
6752 \\
\end{array}$ \\
\hline & & $\begin{array}{c}\text { Elapsed time } \\
9050.060806 \text { seconds }\end{array}$ & $\begin{array}{c}\text { Elapsed time } \\
47.200332 \text { seconds }\end{array}$ \\
\hline & & $\begin{array}{c}\text { Evaluation function } \\
836202248\end{array}$ & $\begin{array}{c}\text { Evaluation function } \\
366145\end{array}$ \\
\hline \multirow{3}{*}{ eil51 } & \multirow{3}{*}{426} & $\begin{array}{c}\text { Best tour Fitness } \\
433 \\
\end{array}$ & $\begin{array}{c}\text { Best tour Fitness } \\
460\end{array}$ \\
\hline & & $\begin{array}{c}\text { Elapsed time } \\
555.017500 \text { seconds }\end{array}$ & $\begin{array}{c}\text { Elapsed time } \\
6.966547 \text { seconds }\end{array}$ \\
\hline & & $\begin{array}{c}\text { Evaluation function } \\
29675501 \\
\end{array}$ & $\begin{array}{c}\text { Evaluation function } \\
38054 \\
\end{array}$ \\
\hline \multirow{3}{*}{ st70 } & \multirow{3}{*}{675} & $\begin{array}{c}\text { Best tour Fitness } \\
696\end{array}$ & $\begin{array}{c}\text { Best tour Fitness } \\
742\end{array}$ \\
\hline & & $\begin{array}{c}\text { Elapsed time } \\
1433.249165 \text { seconds }\end{array}$ & $\begin{array}{c}\text { Elapsed time } \\
9.354369 \text { seconds }\end{array}$ \\
\hline & & $\begin{array}{c}\text { Evaluation function } \\
75327200\end{array}$ & $\begin{array}{c}\text { Evaluation function } \\
63593\end{array}$ \\
\hline
\end{tabular}




\section{Conclusions}

From the results, its noted that when Great Deluge and 2-Opt are used inside ACO algorithm best tour is almost close to the optimal solution and its better than the other methods. But it need more time and evaluation functions than the other methods.

In general, using Great Deluge and 2-Opt with ACO is much more efficient than using Great Deluge and NShift with ACO.

\section{References}

1. Almufti, Saman Mohammed. (2015), "U-Turning Ant Colony Algorithm powered by Great Deluge Algorithm for the solution of TSP Problem.".

2. Marco Dorigo, Thomas Stu" tzle", (2004), Ant Colony Optimization

3.Federico Greco, (2008), Travelling Salesman Problem
4. J. Basic. Appl. Sci. Res., 2(3)2336-2341, (2012), A New Hybrid Algorithm for Optimization Using PSO and GDA

5.D. Karapetyan, G. Gutin, (2012), Efficient Local Search Algorithms for Known and New Neighborhoods for the Generalized Traveling Salesman Problem

6. Andrej Kazakov, (2009), Travelling Salesman Problem: Local Search and Divide and Conquer working together

7. Alfonsas misevičius, armantas ostreika, antanas šimaitis, vilius žilevičius, (2007), vol.36, no.2, improving local search for the traveling salesman problem.

8.Almufti, S. Mohammed (2017), " Using Swarm Intelligence for solving NP-Hard Problems", Academic Journal of Nawroz University, doi ( https ://doi.org/10.25007/ajnu.v6n3a78 ). 